\title{
System integration of processes of ensuring electric power networks safety under the conditions of impact of meteorological factors
}

\author{
Vyacheslav Burlov ${ }^{1}$, Maxim Polyukhovich ${ }^{1}$ \\ ${ }^{1}$ Peter the Great St. Petersburg Polytechnic University, Polytechnicheskaya, 29, St. Petersburg, Russia
}

\begin{abstract}
The problem of the influence of meteorological factors on electric power networks continues to be relevant. For the safe fulfillment of their purpose, electric power networks as an element of the electric power system must guarantee the safety, stability and efficiency of the electric power supply process. To solve the above problems, it is necessary to make decisions based on meteorological observations, since the safety of electric power networks depends on the timely forecasting of meteorological factors. The study examines the possibility of system integration of the process of ensuring the safety of electric power networks and the process of monitoring meteorological factors. In order to increase the level of safety of electric power networks, it is proposed to use a geo information system that collects, processes and transfers meteorological data.
\end{abstract}

\section{Introduction}

The electric power industry is one of the key sectors of the economy of each country and consists of a set of processes for the production, transmission and consumption of electricity. These processes form a combination of economic relations that are part of the state's sustainable development program [1-2]. The operation of electric power facilities is determined, first of all, by the demand for electric energy of the complex of socio-economic and industrial facilities [3-5], and then by the current meteorological conditions.

In the world electric power practice, there are many cases of emergency situations associated with the impact on electric power networks (EPN) of meteorological factors [6-9].

For normal electric power supply to consumers, united power systems have been created, the functioning of which is subject to high requirements for the reliability of electric power supply [10-11] and the quality of electricity [12-14].

Disruptions to the performance of electric power systems are accompanied by a complex of negative phenomena, the consequences of which are of a socioeconomic nature [15-16]. Interruptions in electric power supply and undersupply of electricity to consumers cause significant losses: underutilization or unproductive consumption of resources, underproduction or decrease in product quality, damage to equipment, additional costs for means of production, fires, explosions, etc. [17-21].

These losses are commonly referred to as losses from electric power outages. Damage is a complex economic indicator of the reliability of electric power supply to consumers and is one of the most important characteristics that define the concept of reliability and quality in the electric power industry.

The equipment used for electric power supply to consumers does not exclude the dependence of the process of electric power transmission on the weather [22]. This problem is especially acute for electric power plants located in sparsely populated and inaccessible places.

To increase the level of technical and economic reliability of the electric power system, it is necessary to apply an integrated approach to the safety management of its elements [23]. Currently, in order to improve the level of quality of functioning of geographically distributed objects, all kinds of software and computing systems are used, which allow predicting the state of an object in advance under the influence of various meteorological factors [24-25]

The electric power industry is highly dependent on weather conditions, since almost all of its activity takes place in an open environment. The electric power supply process is influenced by temperature, direction and speed of wind, precipitation, etc. [26-27].

The EPN safety is understood as the creation of conditions for the object to realize its purpose [28].

Ensuring the safety of the EPN is the most important task aimed at reducing the number of emergency situations [29].

The factors affecting the safety of the EPN are subdivided into the following groups:

1. Technical and technological nature (deterioration of electrical wires, supports; congestion of the power transmission line, etc.).

2. Social nature (terrorist acts, sabotage, illegal actions, etc.).

3. Economic nature. 
Ensuring the safety of the electric power supply process should be based on the stable and reliable operation of the equipment of electrical substations, distribution points, power lines. This is achieved, first of all, by observing certain rules for the design, construction, operation and modernization of these facilities. Ensuring safety at the operational stage is based, in addition to the correct dispatch regulation and the mandatory performance of routine maintenance, in carrying out timely repairs, and, if necessary, replacing equipment. The equipment of Russian networks is worn out by more than $70 \%$, and it is quite problematic to require stable operation of the facility. A key feature of the networks is that it is often impossible to take some equipment for repair or simply diagnose it - there is not always a redundant scheme, and even if it is, it is not a fact that the reserve is technically in a better condition than the main line. And from this equipment hospitals, schools, kindergartens and military facilities can be powered.

Meteorological factors, in addition to the main cause of an emergency, can also act as a contributing factor. In a large number of emergencies, the cumulative impact of meteorological conditions and the human factor can be traced.

Let's analyze some meteorological factors and their influence on the EPN.

1. Strong wind. Excessive wind load is the reason for the initiation of a number of causes of power failure [22]. The most common is the overlap of wires by a strong wind on the surrounding objects (tree) due to an unacceptable reduction in the short-circuit distance. Due to vibration and "dancing" of wires the weakening and / or violation of the mechanical strength of supports, wires, insulators has place.

2. Increase or decrease in temperature. Overheating of the overhead line entails a change in the physical and chemical properties of the wire material, causes accelerated wear, corrosion, loss of mechanical strength and, as a result, increases the likelihood of overlap and subsequent short circuit due to violation of safe dimensions [7]. During the period of a significant decrease in ambient air temperatures $\left(\leq-30^{\circ} \mathrm{C}\right)$, strong shaking and vibration, increasing the tension of the wire, in combination with a change in the strength properties of the wire element due to wear, oxidation, vibration by wind loads, lead to a weakening of the connection nodes, followed by a circuit break. This mechanism also occurs during relatively light frosts, but with a sufficiently strong wind.

3. Ice. Ice build-ups appear on the wires of overhead lines mainly in the cold season [9], when warming is replaced by a cold snap and the temperature fluctuates around zero values. With strong winds and high air humidity, the thickness of the ice wall on the wire may be up to $90 \mathrm{~mm}$ or more, which entails damage to the overhead line and huge costs of restoring normal electric power supply. EPN.

And this is only a part of the factors that affect the

Thus, it is obvious that the problem arises of developing a technology for managing the processes of ensuring the safety of the EPN in conditions of the destructive impact of meteorological factors.

\section{Methods}

The implementation of safety processes requires the implementation of certain activities. The basis of the activity is the decision of the decision-maker (DM) [30]. Therefore, in order to create a rationally organized system, it is necessary to have a mathematical model for the DM. To develop actions corresponding to the current state of the environment, it is required to form processes with predetermined properties [23], which is possible only with a synthesis-based approach [30]. Thus, the processes of ensuring safety should function on the basis of the synthesis of a model of managerial decisions. To achieve this goal, a natural science approach (NSA) is applied, based on the object integrity maintenance law (OIML) [28]. The NSA is determined by the integration of the properties of "human reasoning", "surrounding world" and "universal connection of phenomena". The application of the NSA is based on the development of a mathematical model for the DM. The DM's decision model is identical to the EPN safety management process. A model is a description or representation of an object that corresponds to this object and allows one to obtain characteristics about this object [30]. This approach to safety management ensures that the facility fulfills its purpose (supplying electricity to consumers).

Managing safety ensuring processes is a rather difficult task for the DM. This task is very important, because the safety of the controlled object plays an important role in the successful functioning of any organization. The creation and development of the basic principles of ensuring safety is one of the priorities of the governments of states around the world.

To solve these problems, the methodology for solving the problems of the EPN safety ensuring management should give the DM a condition for the existence of an activity process. The solution is based on the system integration of the properties of "human reasoning", "surrounding world" and "universal connection of phenomena". The solution is based on the model [30].

To carry out activities appropriate to the situation, it is necessary to have an adequate mathematical model of a managerial decision. The DM's managerial decision is a backbone factor in the successful operation of the object. What is the mathematical model of the DM's decision such is the result of the object's activity.

Only two approaches of system development (model) are known [23]:

- system development based on analysis;

- system development based on synthesis.

The authors noted (Goode, H. H., Machol, R. E. (1957)) that the first approach is the most popular. It is based on an enumeration of options. The disadvantage is that it does not allow to guarantee the achievement of the goal of the activity. The second approach allows you to guarantee the achievement of the goal of the activity. But for this you need to know the law of construction and functioning of the system being developed. 
For systems created by nature, you can apply the known laws of nature.

For systems created by man, it is necessary to know the law of construction and functioning of the system being created. Academician of the Academy of Sciences of the USSR P.K. Anokhin substantiated and experimentally confirmed that for the synthesis of a system it is necessary to identify the "basic pattern" of the general theory of functional systems. In this study, the solution is used to synthesize a safety management model.

Thus, it is necessary to synthesize a mathematical model of the DM. The mathematical model of the solution allows the implementation of resources in the interests of achieving the required level of efficiency of activity (electricity supply to consumers).

In accordance with the developed NSA, each process must be represented by three components corresponding to the properties of "objectivity", "integrity" and "variability" (or the concepts of "object", "purpose" and "action", respectively).

Having decomposed the concept of "managerial decision" into three main elements: "situation", "infoanalytic work" and "decision", it is necessary to proceed to the synthesis of a decision model (fig. 1).

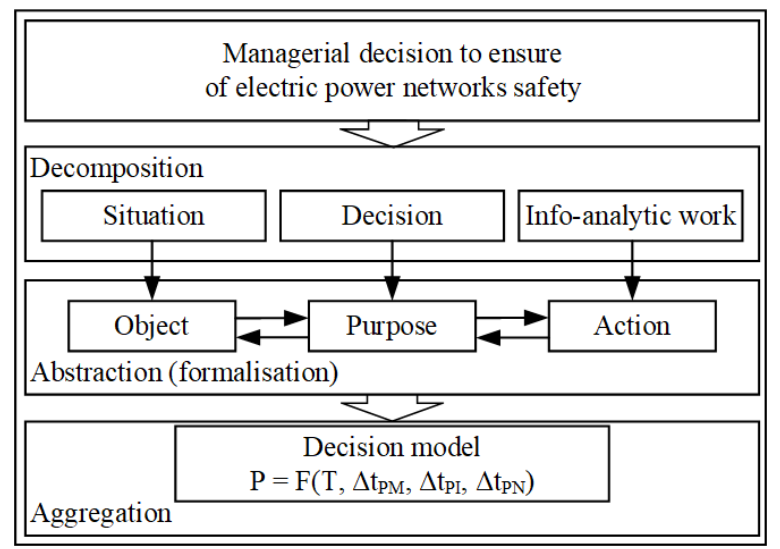

Fig. 1. Block diagram of the deployment of the content of the synthesis process of the mathematical model of the solution

At the first level, applying the decomposition method, the decision is divided into three elements: "situation", "decision" and "info-analytic work", which correspond to "object", "purpose" and "action". Applying the method of abstraction at the second level, the "object" ("situation") is identified with the frequency of manifestations of the task (problem) in front of the DM $-\Delta t_{P M}$. "Purpose" ("Decision") is identified with the frequency of neutralization of the problem (according to the average time of an adequate response to the problem) by the DM $-\Delta t_{P N}$. "Action" ("info-analytic work") is identified with the frequency of identification of the problem (average time of situation recognition) $-\Delta t_{P I}$. Temporal characteristics are justified by the fact that only temporary resources are irreplaceable for the DM. Also, the results of research on the theory of functional systems by Academician of the Academy of Sciences of the USSR P.K. Anokhin show that a person's decision is formed in the schemes "excitement", "recognition", "reaction to the situation".

Thanks to the application of methods of decomposition, abstraction and aggregation, the concept of "managerial decision" is transformed into an aggregate - a mathematical model of a managerial decision of the following form:

$$
P=F\left(T, \Delta t_{P M}, \Delta t_{P I}, \Delta t_{P N}\right)
$$

This condition provides the required value of the indicator of the efficiency of the management system for the safety processes of the facility. Since the basic model of a managerial decision has three elements, the block diagram of management should be presented as follows (fig. 2).

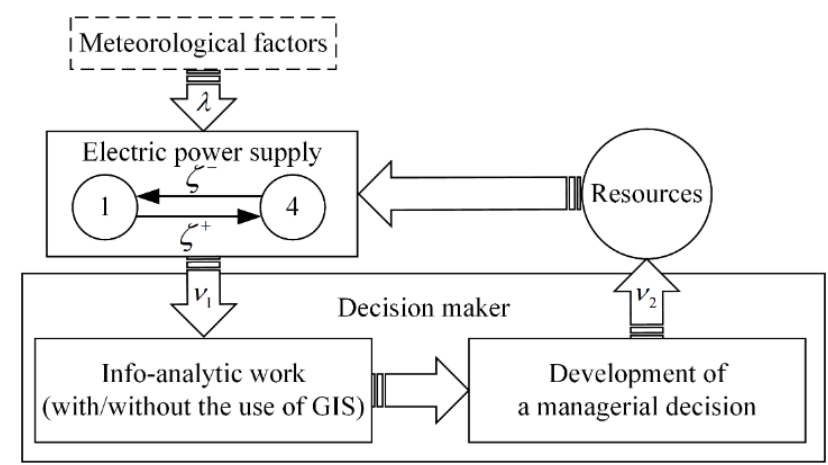

Fig. 2. Block diagram of the management process of ensuring the safety of the EPN

In fig. $2 \lambda=1 / \Delta t_{P M}$ (the inverse amount of the average time of the problem manifestation), $v_{1}=1 / \Delta t_{P I}$ (the inverse amount of the average time of the problem identification), $v_{2}=1 / \Delta t_{P N}$ (the inverse amount of the average time of the problem neutralization), $\zeta^{+}=1 / T$ (the inverse amount of the average execution time of the target process), $\zeta^{-}$- frequency of disruption of the target process (once an hour, once a day, etc.).

The DM can perform two functions in various combinations:

- identify (recognize) the problem;

- neutralize (use the resources of the safety system) the problem.

Thus, the DM's decision model is characterized by four main states (fig. 3):

1 - DM does not identify and does not neutralize;

2 - DM identifies and does not neutralize;

3 - DM neutralizes and does not identify;

4 - DM identifies and neutralizes.

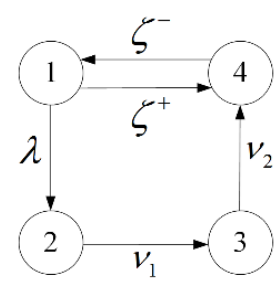

Fig. 3. The graph of states of the process of forming the managerial decision of the DM 
In accordance with the described feature of the managerial decision, it is necessary to introduce the probabilities of finding our system for managing the processes of ensuring the safety of the EPN in these four states. Accordingly, four probabilities $\mathrm{P}_{1}, \mathrm{P}_{2}, \mathrm{P}_{3}, \mathrm{P}_{4}$ are obtained, corresponding to the system being in states "1", "2", "3", "4". The decision formation process can be viewed as a Markov chain. Since this approach does not sufficiently take into account the dynamics of the process, in this study it is advisable to use continuous Markov chains. To implement this approach, it is necessary to formulate a system of Kolmogorov-Chapman differential equations. Let's assume that the system is in the initial state "1". When a problem arises under the influence of intensity $\lambda$, it goes into state "2", that is, the state of problem identification. From this state, the system, under the influence of intensity $v_{1}$ goes into state " 3 ". In the current state, the system begins the process of neutralizing the problem with intensity $v_{2}$ and transfers the system to state "4", in which the DM identifies and neutralizes the problem. Then the system returns to the initial state "1", that is, the object fulfills its purpose. This study proposes a process for identifying a meteorological problem based on GIS. This approach will reduce the time it takes to identify the problem, so the DM will have more time to develop a response action.

Taking into account certain assumptions [28, 30], the Kolmogorov-Chapman system of differential equations is used. The solution to a linear algebraic system of equations is presented in the form of the following relations (equations 1-4).

The probabilities of finding the management system for the processes of ensuring the safety of the EPN in certain states:

$$
\begin{aligned}
& P_{1}=\frac{\zeta^{-} \cdot v_{1} \cdot v_{2}}{\zeta^{-} \cdot \lambda \cdot v_{1}+\zeta^{-} \cdot \lambda \cdot v_{2}+\zeta^{+} \cdot v_{1} \cdot v_{2}+\zeta^{-} \cdot v_{1} \cdot v_{2}+\lambda \cdot v_{1} \cdot v_{2}} \\
& P_{2}=\frac{\zeta^{-} \cdot \lambda \cdot v_{2}}{\zeta^{-} \cdot \lambda \cdot v_{1}+\zeta^{-} \cdot \lambda \cdot v_{2}+\zeta^{+} \cdot v_{1} \cdot v_{2}+\zeta^{-} \cdot v_{1} \cdot v_{2}+\lambda \cdot v_{1} \cdot v_{2}} \\
& P_{3}=\frac{\zeta^{+} \cdot \lambda \cdot v_{1}}{\zeta^{-} \cdot \lambda \cdot v_{1}+\zeta^{-} \cdot \lambda \cdot v_{2}+\zeta^{+} \cdot v_{1} \cdot v_{2}+\zeta^{-} \cdot v_{1} \cdot v_{2}+\lambda \cdot v_{1} \cdot v_{2}} \\
& P_{4}=\frac{\zeta^{+} \cdot v_{1} \cdot v_{2}+\lambda \cdot v_{1} \cdot v_{2}}{\zeta^{-} \cdot \lambda \cdot v_{1}+\zeta^{-} \cdot \lambda \cdot v_{2}+\zeta^{+} \cdot v_{1} \cdot v_{2}+\zeta^{-} \cdot v_{1} \cdot v_{2}+\lambda \cdot v_{1} \cdot v_{2}}
\end{aligned}
$$

\section{Results}

An indicator of the effectiveness of the functioning of the safety management system is the likelihood that each problem (task) arising during operation will be identified and neutralized.

This indicator of the effectiveness is determined by the ratio:

$$
\left.P_{4}=\frac{\zeta^{-} \cdot v_{1} \cdot v_{2}+\lambda \cdot v_{1} \cdot v_{2}}{\zeta^{+} \cdot \lambda \cdot v_{1}+\zeta^{+} \cdot \lambda \cdot v_{2}+\zeta^{+} \cdot v_{1} \cdot v_{2}+\zeta^{-} \cdot v_{1} \cdot v_{2}+\lambda \cdot v_{1} \cdot v_{2}}\right)
$$

Consider the impact on the control object (EPN) of the wind load.

A meteorological threat in the form of a strong wind is especially relevant for the EPN in the following cases: in case of violation of the maximum allowable sag of the wires, with an increased maximum allowable distance between adjacent supports, in the presence of vegetation under the wires. In these cases, a short circuit, breaks or

\begin{tabular}{|c|c|c|}
\hline $\begin{array}{l}\text { System } \\
\text { transitions }\end{array}$ & $\begin{array}{c}\text { Without the use of } \\
\text { GIS }\end{array}$ & With the use of GIS \\
\hline $1-2$ & 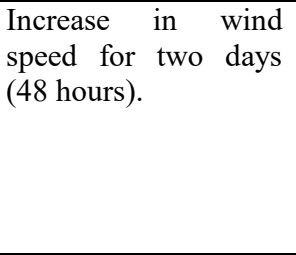 & $\begin{array}{l}\text { When analyzing the } \\
\text { GIS data, it was } \\
\text { recorded that in two } \\
\text { days the wind speed is } \\
\text { expected to increase } \\
\text { above the permissible } \\
(48 \mathrm{~h}) \text {. }\end{array}$ \\
\hline $2-3$ & $\begin{array}{l}\text { The DM receives } \\
\text { reports on the state of } \\
\text { the weather during the } \\
\text { day ( } 24 \text { hours) and } \\
\text { predicts a wire break } \\
\text { in area } N \text { ( } 8 \text { hours). In } \\
\text { total, } 32 \text { hours were } \\
\text { spent on identifying } \\
\text { the problem. }\end{array}$ & $\begin{array}{l}\text { The DM predicts a } \\
\text { wire break in the } \mathrm{N} \\
\text { region ( } 1 \text { hour). }\end{array}$ \\
\hline $3-4$ & $\begin{array}{l}\text { The monitoring of the } \\
\text { state of structures to } \\
\text { protect the wires of } \\
\text { overhead lines from } \\
\text { wind influences } \\
\text { (vibration dampers) } \\
\text { and their replacement } \\
\text { in case of non- } \\
\text { compliance with the } \\
\text { requirements (8 } \\
\text { hours) is carried out. }\end{array}$ & $\begin{array}{l}\text { The monitoring of the } \\
\text { state of structures to } \\
\text { protect the wires of } \\
\text { overhead lines from } \\
\text { wind influences } \\
\text { (vibration dampers) } \\
\text { and their replacement } \\
\text { in case of non- } \\
\text { compliance with the } \\
\text { requirements (8 } \\
\text { hours) is carried out. }\end{array}$ \\
\hline $4-1$ & \begin{tabular}{lr}
\multicolumn{2}{l}{ The object fulfilled its } \\
purpose (supplying \\
consumers \\
electricity) \\
hours).
\end{tabular} & $\begin{array}{lr}\text { The object fulfilled its } \\
\text { purpose (supplying } \\
\text { consumers } \\
\text { electricity) } \\
\text { hours). }\end{array}$ \\
\hline
\end{tabular}
burnout of power lines may occur. Let's compose an algorithm of actions according to fig. 3 (table 1).

Table 1. Description of transitions of the management system for the processes of ensuring the safety of the EPN

Indicators of the process management system for ensuring the safety of the EPN without the use of GIS: $\lambda$ $=0,021, v_{1}=0,04, v_{2}=0,125, \zeta^{+}=0,020$. The efficiency indicator of such a system is: $P_{4}=0,35$.

Indicators of the process management system for ensuring the safety of the EPN with the use of GIS: $\lambda=$ $0,021, v_{1}=1, v_{2}=0,125, \zeta^{+}=0,020$. The efficiency indicator of such a system is: $P_{4}=0,46$.

Let us substitute the predicted values into expression (5) and determine the indicator of the effectiveness of the functioning of the integrated management system for the processes of ensuring the safety of the EPN at different values of the frequency of disruption of the target process (from disruption every hour to disruption once a day). The obtained indicators are shown in the fig. 4. 


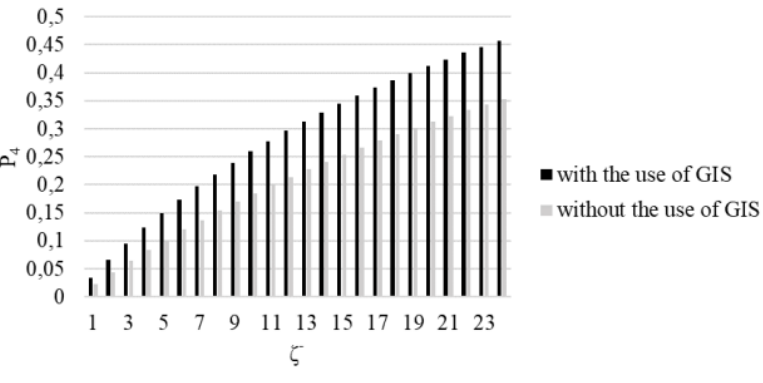

Fig. 4. The dependence of the probability $P_{4}$ on the frequency $\zeta^{-}$

Analyzing the obtained result, it can be concluded that the use of the GIS as a tool for monitoring meteorological factors is justified and increases the efficiency of the system for managing the safety processes of the EPN.

\section{Discussion}

This study presents a synthesis-based safety management concept that meets the requirements for the sustainable operation of electric power networks under the influence of meteorological factors.

This paper describes an approach to integrate safety processes for the sustainable operation of the facility. It is proposed to use the GIS as a tool for monitoring meteorological factors. A comparative analysis of the efficiency indicators of safety systems for the processes of ensuring the safety of the EPN without and with the use of the GIS is presented.

Thus, this study proposes an approach to managing a sustainable electric power supply in conditions of the destructive impact of meteorological factors.

\section{Conclusions}

The presented simulation of safety management processes allows to guarantee reliable and safe electric power supply to consumers. Thus, one of the fundamental aspects of sustainable development has been realized. In further studies, it is planned to consider additional factors affecting the performance indicator of the safety management system of electric power networks.

The reported study was funded by RFBR, project number 20-38-90225.

\section{References}

1. N. Sadullaev, S. Nematov, Micro-grid based power supply of remote consumers located away from the centralized power grid. Paper presented at the Proceedings of IEEE International Conference on Advent Trends in Multidisciplinary Research and Innovation, ICATMRI 2020 (2020)

2. S. Abhishek, G. Abhinav, A. Kumar, P. Mala, Transmission lines management system for smart grids. Paper presented at the Proceedings of 2020 IEEE International Women in Engineering (WIE)
Conference on Electrical and Computer Engineering, WIECON-ECE 2020, 44-47 (2020)

3. A. Anastasiadis, G. Kondylis, A. Polyzakis, G. Vokas, Energy Procedia, Effects of increased electric vehicles into a distribution network, 157, 586-593 (2019)

4. Y. Chen, L. Zhang, P. Xu, A. Di Gangi, Energy, Electricity demand response schemes in China: Pilot study and future outlook, 224 (2021)

5. P. Li, Z. Wang, J. Wang, T. Guo, Y. Yin, Applied Energy, A multi-time-space scale optimal operation strategy for a distributed integrated energy system, 289 (2021)

6. A. Shilin, A. Shilin, S. Dementiev, Smart electromechanical systems in electric power engineering: Concept, technical realization, prospects (2019)

7. S. Khatoon, Ibraheem, A. Singh, Priti, Effects of various factors on electric load forecasting: An overview. Paper presented at the Proceedings of 6th IEEE Power India International Conference, PIICON 2014, 63 (2014)

8. J. Grabara, J. Kapuściński, S. Kot, Distribution of electricity in the context of meteorological phenomena. Paper presented at the Proceedings of the 6th International Scientific Symposium on Electrical Power Engineering, ELEKTROENERGETIKA 2011, 18-20 (2011)

9. Y. Li, J. Han, T. Wang, Dianli Zidonghua Shebei/Electric Power Automation Equipment, Ice monitoring system of overhead electrical power lines, 29(11), 112-115 (2009)

10. I. Ozer, S. Efe, H. Ozbay, Alexandria Engineering Journal, A combined deep learning application for short term load forecasting 60(4), 3807-3818 (2021)

11. O. Kondrateva, M. Romashov, O. Loktionov, Analysis of the applicability of key risk assessment methods for solving problems of reducing accidents at energy facilities. Paper presented at the Proceedings of the 3rd 2021 International Youth Conference on Radio Electronics, Electrical and Power Engineering, REEPE 2021, (2021)

12. G. Li, An analysis of the application of energy storage technology in power systems. Paper presented at the IOP Conference Series: Earth and Environmental Science, 692(2) (2021)

13. C. Trentini, W. de Oliveira Guedes, L. de Oliveira, B. Dias, V. Ferreira, Journal of Control, Automation and Electrical Systems, Maintenance planning of electric distribution Systems-A review, 32(1), 186-202 (2021)

14. S. Makasheva, P. Pinchukov, J. Szoltysek, The power quality as a pretext for developing smart city concepts. Paper presented at the 2020 International MultiConference on Industrial Engineering and Modern Technologies, FarEastCon 2020 (2020)

15. C. Sur, Journal of Rural Development, Study on the impact of grid electricity in powering the expansion of healthcare services and facilities in Sagar island, 36(3), 397-418 (2017)

16. A. Usypko, A. Uljanov, Assessment of occupational risk of enterprises producing energy using sources of 
ionizing radiation. Paper presented at the E3S Web of Conferences, 221 (2020)

17. N. Salim, J. Jasni, M. Othman, International Journal of Electrical Power and Energy Systems, Reliability assessment by sensitivity analysis due to electrical power sequential tripping for energy sustainability, 126 (2021)

18. Y. Hassan, F. Tuaimah, Recent Patents on Engineering, Reduction strategy for electrical loads based on demand priority in power system, 15(3), 388395 (2021)

19. G. Dimov, S. Tzvetkova, Y. Lozanov, Influence of the type of electrical distribution network on the indices of continuity of the power supply. Paper presented at the 2020 12th Electrical Engineering Faculty Conference, BulEF 2020, (2020)

20. J. Clavijo-Blanco, J. Rosendo-Macías, Electric Power Systems Research, Failure rates in distribution networks: Estimation methodology and application, 185 (2020)

21. S. Shield, S. Quiring, J. Pino, K. Buckstaff, Energy, Major impacts of weather events on the electrical power delivery system in the United States, 218 (2021)

22. N. Rodrigues, F. Janeiro, P. Ramos, Influence of weather conditions in power quality events. Paper presented at the Proceedings - 2020 IEEE 14th International Conference on Compatibility, Power Electronics and Power Engineering, CPEPOWERENG 2020, 219-223 (2020)

23. V. Burlov, O. Lepeshkin, M. Lepeshkin, D. Solovev, Organization of management of social and economic systems of the region in the conditions of the required technosphere safety. Paper presented at the IOP Conference Series: Earth and Environmental Science, 459(2) (2020)

24. L. Jones, P. Hobbs, Remote Sensing, The application of terrestrial LiDAR for geohazard mapping, monitoring and modelling in the british geological survey, 13(3) (2021)

25.S. Gorbanev, A. Kulichenko, V. Fedorov, V. Dubyansky, Y. Novikova, A. Kovshov, . . . O. Shayahmetov, Gigiena i Sanitariya, Organization of an interregional monitoring system using gis technologies by the example of Russian Federation arctic zone, 97(12), 1133-1140 (2018)

26. V. Malladi, R. Mendoza-Arriaga, S. Tompaidis, Operations Research, Modeling dependent outages of electric power plants, 68(1), 1-15 (2019)

27. J. Fan, Q. Liang, X. Liang, H. Tatano, Y. Kajitani, Y. Wei, Natural Hazards, National vulnerability to extreme climatic events: The cases of electricity disruption in china and japan, 71(3), 1937-1956 (2014)

28. V. Burlov, M. Grachev. Mathematical model of management decision making that takes into account the technical and human factors. Paper presented at the CEUR Workshop Proceedings, 2711, 597-606 (2020)

29. V. Senchenko, T. Kaverzneva, I. Skripnik, J. Idrisova, Investigacion Operacional, Optimal location of communication lines and power lines on common support, 41(2), 188-199 (2020)
30. V. Burlov, A. Andreev, F. Gomazov, Mathematical model of human decision - A methodological basis for the realization of the human factor in safety management. Paper presented at the Procedia Computer Science, 145, 112-117 (2018) 